https://doi.org/10.11646/zoosymposia.20.1.3

http://zoobank.org/urn:Isid:zoobank.org:pub:E873AF5D-BF2A-4B90-A732-38C2E319E88B

\title{
Introducing a survey of mite lifespans: How long do Acari live?
}

\author{
ZHI-QIANG ZHANG ${ }^{1,2}$ \\ ${ }^{1}$ Manaaki Whenua-Landcare Research, Private Bag 92170, Auckland, New Zealand. \\ ”zhangZ@landcareresearch.co.nz; ○ https://orcid.org/0000-0003-4172-0592 \\ ${ }^{2}$ School of Biological Sciences, Centre for Biodiversity \& Biosecurity, The University of Auckland, Auckland, New Zealand
}

"The reasons for some animals being long-lived and others short-lived, and, in a word, causes of the length and brevity of life call for investigation.

We find this distinction affecting not only entire genera opposed as wholes to one another, but applying also to contrasted sets of individuals within the same species."

— "On Longevity and Shortness of Life" by Aristotle (350 B.C.), English translation by G.R.T. Ross

How long do animals live and why are some long-lived whereas others short-lived? These questions have long fascinated scholars, including Aristotle. Incidentally, it is also Aristotle who first named mites "Acari" according to new research on the Greek origin of acarology by Zaborowski \& Daszkiewicz (2017):

"And on honeycomb, the one that grew old, there are, as well as in the wood, animals which seem to

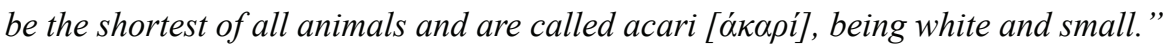

— "History of Animals" by Aristotle

Is Aristotle the reason we are conducting a survey on lifespans in the Acari here? Not really, or not entirely, to be more precise. I have been interested in the ecology and evolution of animal aging and lifespan, and have collaborated with numerous students and colleagues on this subject in recent years. As acarologists, we very much appreciate the life history diversity in the Acari (Houck 1994) and understand the ease with which many species of mites can be cultured in the laboratory and experimentally manipulated to address questions in biology. We have used different groups of mites as experimental systems to study several aspects of animal aging and lifespan: e.g., the extension of lifespan by different methods of diet restriction (Li \& Zhang 2019, 2021a; Lee et al. 2020), the effects of pathogenic fungi on mite host lifespan (Liu et al. 2019), the effects of delayed/repeated mating (Li \& Zhang 2021a,c), intrasexual and intersexual interactions within species (Li \& Zhang 2021b) or stress induced by predators (Wei \& Zhang 2019; Li \& Zhang 2020) on the lifespan and/or other related life history traits. During our research, it becomes apparent that there is a vast body of literature on mite lifespans scattered in many journals and books, yet mites (and indeed many other arthropods) are very poorly represented in the gerontological literature and databases, which are heavily focused on vertebrate models and selected invertebrates such as Drosophila. For example, over $98 \%$ of the records for lifespans in "AnAge: The Animal Ageing and Longevity Database" are for Chordata, which only accounts for about $5 \%$ of all animal species (Fig. 1); the Arthropoda, which accounts for over $78 \%$ species of all animals, are poorly represented in this database and no mite species are included. Although selected model species provide useful in-depth studies of some subjects, it is crucial to employ a comparative approach to use different animal species across the tree of life in aging research (Cohen 2018). Houck (1994) collected several excellent reviews of life history modifications in different groups, with some coverages on mite lifespans. Our project here is focused on mite lifespan data. Numerous mite specialists provided surveys of lifespan and related life history data such as 
immature development time for their groups, including Sarcoptiformes (Oribatida by Pfingstl \& Schatz 2021; Winterschmidtiidae by Zhang 2021a and Eriophyoidea by Ozman-Sullivan \& Sullivan 2021), Trombidiformes (Tydeidae by Johann \& Da Silva 2021, Anystidae by Zhang 2021b and Cheyletidae by Zheng \& Xia 2021) and Mesostigmata (Blattisociidae by Zhang and Xie 2021). A second volume in the next year will include lifespan surveys on other mite taxa. I hope the comprehensive data reviewed and analysed in this series of surveys will appeal to both acarologists and non-acarologists and will stimulate further research on both the patterns and mechanisms of animal aging and lifespan.

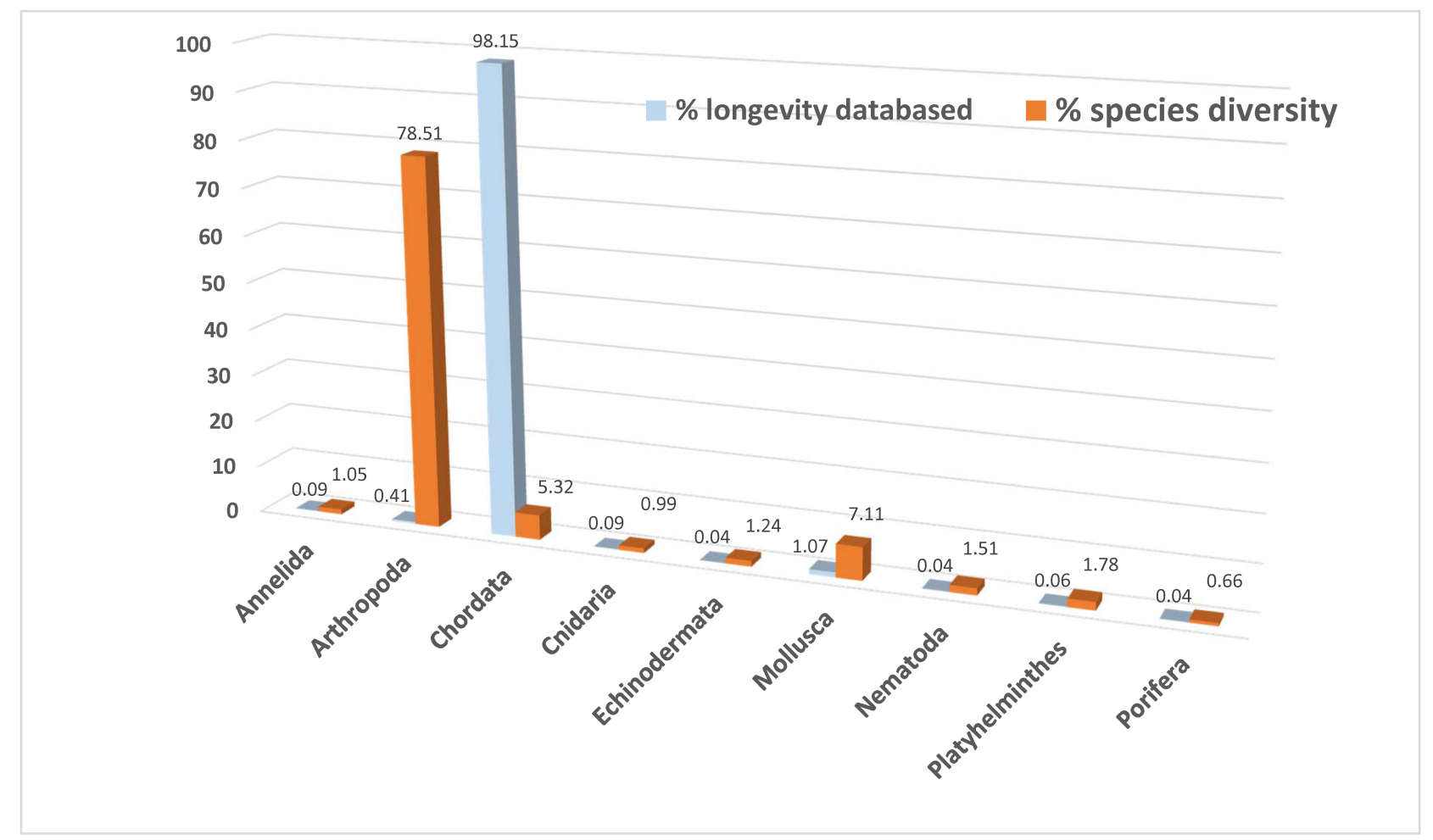

FIGURE 1. Animal phyla with \% of longevity records databased in AnAge (left columns) versus \% species diversity of these phyla (right columns; data from Zhang 2013). AnAge is The Animal Ageing and Longevity Database available from https://genomics.senescence.info/species/index.html (data from Build 14 dated 14 Oct 2017; last accessed on 29 Dec 2021.

\section{Acknowledgement}

I thank my co-editor Dr Qing-Han Fan (Plant Health \& Environment Laboratory, Ministry for Primary Industries, Auckland, New Zealand) for sharing the editing for this special volume. I also thank all the authors and reviewers for their contributions to this volume. Qing-Han Fan and Lilian Zhang (The University of Auckland, Auckland, New Zealand) kindly reviewed the draft of this manuscript and provided comments.

\section{References}

Cohen, A.A. (2018) Aging across the tree of life: The importance of a comparative perspective for the use of animal models in aging. Biochimica et Biophysica Acta (BBA) - Molecular Basis of Disease 1864 (9), 2680-2689. https://doi.org/10.1016/j.bbadis.2017.05.028

Houck, M. (Ed.) (1994) Mites. Ecological and Evolutionary Analyses of Life-History Patterns. Chapman and Hall, New York, $357 \mathrm{pp}$.

Johann, L. \& Da Silva, G.L. (2021) How long do Tydeidae live? Zoosymposia, 20, 71-76. https://doi.org/10.11646/zoosymposia.20.1.7

Lee, M.H., Fan, Q.-H., Yu, L.-C. \& Zhang, Z.-Q. (2020) Caloric restriction extends lifespan of mothers at the expense of offspring survival in a predatory mite (Neoseiulus cucumeris). Systematic and Applied Acarology, 25 (11), $1948-1962$. 
https://doi.org/10.11158/saa.25.11.2

Li, G-Y. \& Zhang, Z.-Q. (2019) The sex- and duration-dependent effects of intermittent fasting on lifespan and reproduction of spider mite Tetranychus urticae. Frontiers in Zoology, 16 (1), 10. https://doi.org/10.1186/s12983-019-0310-4

Li, G-Y. \& Zhang, Z.-Q. (2020) Development, lifespan and reproduction of spider mites exposed to predator-induced stress across generations. Biogerontology, 20, 871-882 https://doi.org/10.1007/s10522-019-09835-0

Li, G-Y. \& Zhang, Z.-Q. (2021a) Age-specific mortality and fecundity of a spider mite under diet restriction and delayed mating. Insect Science. https://doi.org/10.1111/1744-7917.12948

Li, G-Y. \& Zhang, Z.-Q. (2021b) The costs of social interaction on survival and reproduction of arrhenotokous spider mite Tetranychus urticae. Entomologia Generalis, 41 (1), 49-57. https://doi.org/10.1127/entomologia/2020/0911

Li, G-Y. \& Zhang, Z.-Q. (2021c) Sex-specific response to delayed and repeated mating in spider mite Tetranychus urticae. Bulletin of Entomological Research, 111 (1), 49-56. https://doi.org/10.1017/S0007485320000292

Liu, J.-F., Zhang, Z.-Q., Beggs, J.R., Wei, X.-Y. (2019) Influence of pathogenic fungi on the life history and predation rate of mites attacking a psyllid pest. Ecotoxicology and Environmental Safety, 183, 109585. https://doi.org/10.1016/j.ecoenv.2019.109585

Ozman-Sullivan, S.K. \& Sullivan, G.T. (2021) How long do eriophyoid mites live? Zoosymposia, 20, 35-70. https://doi.org/10.11646/zoosymposia.20.1.6

Pfingstl, T. \& Schatz, H. (2021) A survey of lifespans in Oribatida excluding Astigmata (Acari). Zoosymposia, $20,7-27$. https://doi.org/10.11646/zoosymposia.20.1.4

Wei, X.-Y. \& Zhang, Z.-Q. (2019) A modified Munger cell for testing long-term effects of predator-induced stress on prey: an example using Tyrophagus putrescentiae (Acaridae) and its predator Neoseiulus cucumeris. Systematic and Applied Acarology, 24 (12), 2285-2289. https://doi.org/10.11158/saa.24.12.1

Zaborowski, R. \& Daszkiewicz, P. (2017) About the Greek origin of acarology: a short note on Argas and the Acari. Biological Letters, 5 3(1), 3-7. https://doi.org/10.1515/biolet-2017-0001

Zhang, Z.-Q. (2013) Animal biodiversity: an update of classification and diversity in 2013. Zootaxa, 3703, 5-11. https://doi.org/10.11646/zootaxa.3703.1.3

Zhang, N. \& Xie, L.-X. (2021) The lifespans of the potential biological control agents in the family Blattisociidae (Acari: Mesostigmata). Zoosymposia, 20, 91-103. https://doi.org/10.11646/zoosymposia.20.1.10

Zhang, Z.-Q. (2021a) A survey of lifespan in Winterschmidtiidae (Sarcoptiformes: Astigmata). Zoosymposia, $20,28-34$. https://doi.org/10.11646/zoosymposia.20.1.5

Zhang, Z.-Q. (2021b) How long do whirligig mites live? A survey of lifespan in Anystidae (Acari: Trombidiformes). Zoosymposia, $20,77-84$. https://doi.org/10.11646/zoosymposia.20.1.8

Zheng, Z.-H. \& Xia, B. (2021) The characteristics of lifespan in Cheyletidae and its response to environmental factors. Zoosymposia, 20, 85-90.

https://doi.org/10.11646/zoosymposia.20.1.9 